\title{
Comparison of Phenylephrine and Ephedrine in the Treatment of Hypotension and Its Effects on the Foetus after Subarachnoid Block for Caesarean Section
}

\author{
Khawer Muneer ${ }^{1}$, Hina Khurshid'2 , H. K. Venkatesh ${ }^{3}$ \\ ${ }^{1}$ Department of Anaesthesiology and Critical Care, GMC, Srinagar, Jammu and Kashmir, India. ${ }^{2}$ Department of \\ Anaesthesiology, SKIMS Medical College, Bemina, Srinagar, Jammu and Kashmir, India. ${ }^{3}$ Department of \\ Neuroanaesthesia, Apollo Hospital, Bangalore, Karnataka, India.
}

\section{ABSTRACT}

\section{BACKGROUND}

Subarachnoid block has been widely used for caesarean sections and is found to be safe. Hypotension being the most common complication may adversely affect both the mother and foetus. Different measures used to treat this hypotension include preloading with crystalloids/colloids and treatment with vasopressors. The standard choice of vasopressor agents such as ephedrine and phenylephrine is still a controversial issue. It is therefore important to compare the efficacy of the two drugs in the prevention and treatment of maternal hypotension after subarachnoid block and particularly assess their effect on the foetus. The purpose of this study was to assess and compare the foetal acid-base status and APGAR score following administration of bolus dose of ephedrine or phenylephrine that was given intravenously for maintenance of arterial blood pressure during lower segment caesarean section (LSCS) under a subarachnoid block.

\section{METHODS}

100 parturients (18 to 35 years) scheduled for elective caesarean section under subarachnoid block were selected and divided into two groups of 50 each. Group P received $50 \mathrm{mcg}$ i.v bolus of phenylephrine and Group E received $6 \mathrm{mg}$ of ephedrine IV bolus whenever the blood pressure dropped $20 \%$ from baseline or systolic blood pressure < $90 \mathrm{mmHg}$. Haemodynamic parameters were measured in all patients. APGAR scores at 1 and 5 minutes following delivery of baby were assessed and cord blood was obtained for acid-base status analysis immediately following delivery.

\section{RESULTS}

Hemodynamic parameters including heart rate, systolic blood pressure, diastolic blood pressure, and mean arterial pressure did not show any significant difference between the two groups, however, Group E showed higher heart rates. The difference in umbilical artery $\mathrm{pH}(\mathrm{P}$-value $<0.001)$ and base excess $(\mathrm{P}$-value $=$ 0.004) was statistically significant with Group E showing lower $\mathrm{pH}$ and higher base excess values than Group P. There was no statistically significant difference in neonatal APGAR scores between the two groups.

\section{CONCLUSIONS}

Phenylephrine and ephedrine are equally efficient in managing hypotension during subarachnoid block for caesarean delivery. Thus, either vasopressor can be used although phenylephrine may be a better choice.

\section{KEY WORDS}

Caesarean Section, Phenylephrine, Ephedrine.
Corresponding Author: Dr. Khawer Muneer, Senior Resident,

Department of Anaesthesiology and Critical Care, GMC, Srinagar, Jammu and Kashmir, India E-mail: khawermuneer@gmail.com

DOI: $10.14260 / j e m d s / 2021 / 763$

How to Cite This Article:

Muneer $K$, Khurshid H, Venkatesh HK. Comparison of phenylephrine and ephedrine in the treatment of hypotension and its effects on the foetus after subarachnoid block for caesarean section. J Evolution Med Dent Sci 2021;10(44):37753780, DOI: 10.14260/jemds/2021/763

Submission 02-06-2021, Peer Review 21-11-2021, Acceptance 28-11-2021, Published 30-11-2021.

Copyright (c) 2021 JEMDS. This is an open access article distributed under Creative Commons Attribution License [Attribution 4.0 International (CC BY 4.0)] 


\section{BACKGROUND}

Anaesthesia to a parturient requires the highest degree of care as the anaesthesiologist has to look after two individuals, the mother and the fetus. ${ }^{1}$ Subarachnoid block has been widely used for caesarean sections and has been found to be efficacious and safe. ${ }^{2}$ Hypotension is the most common complication of subarachnoid block in obstetric patients. ${ }^{3}$ Its incidence has been reported to be 80 - 90 percent. $^{4}$

Hypotension during spinal anaesthesia for caesarean section is secondary to the sympathetic blockade, and it can be harmful to both the foetus and the mother. The harmful effects that can occur are a reduction in uterine and placental blood flow, disruption of foetal oxygenation and foetal acidosis, and maternal symptoms of reduced cardiac output. ${ }^{5}$ Other symptoms such as nausea, vomiting and altered consciousness may also occur. ${ }^{6}$ Prompt and effective treatment is essential to prevent these effects. 7,8

Different measures used to treat hypotension include preloading with colloids/crystalloids and the use of vasopressors. ${ }^{9}$ Vasopressors used for the treatment of hypotension should have high efficacy and the ability to use liberal doses to maintain maternal blood pressure near the normal and have minimal effect on the fetus. ${ }^{10}$

Ephedrine, which has a strong beta-adrenergic and weaker alpha-adrenergic effect has been traditionally recommended in this situation, but its use has been challenged owing to potential complications like supraventricular tachycardia, tachyphylaxis and foetal acidosis. ${ }^{11}$ Previous studies have reported that increased blood pressure caused by ephedrine is related to the preservation of uterine and placental blood flow, especially because of its beta-adrenergic action. ${ }^{12,13}$ However, other studies have suggested that ephedrine can reduce umbilical pH without affecting APGAR scores. ${ }^{14,15}$

Phenylephrine has been used for the prevention and treatment of spinal-induced hypotension in caesarean delivery. Phenylephrine is a potent direct-acting alphaagonist that can be used for the prevention and treatment of maternal hypotension. Foetal acidosis has not been demonstrated when phenylephrine is used liberally to maintain maternal blood pressure and prevent symptoms. ${ }^{16}$

Standard choice of vasopressor agents such as ephedrine and phenylephrine for treatment of spinal hypotension in caesarean sections is still a controversial issue. ${ }^{17}$ It is, therefore important to compare the efficacy of the two drugs in the prevention and treatment of maternal hypotension during the spinal block to assess foetal changes using Apgar score, and side effects of ephedrine and phenylephrine.

This study was designed to compare the effect of ephedrine and phenylephrine administration to treat hypotension following subarachnoid block for caesarean section on foetal acid-base status, APGAR score as well as their adverse effects.

\section{METHODS}

\section{Primary Outcome}

1. Umbilical artery $\mathrm{pH}$ and base excess

2. APGAR scores at 1 and 5 minutes after birth

\section{Secondary outcome}

1. Maternal blood pressure and heart rate

2. Several episodes of hypotension and the number of doses of vasopressor use.

3. Incidence of nausea, vomiting or any other complication.

This was a comparative study conducted on 100 parturient of 18 to 35 yrs. of age scheduled for caesarean section under spinal anaesthesia in the Department of Anaesthesiology at the Apollo hospital, Bangalore from $1^{\text {st }}$ July 2016 to $30^{\text {th }}$ June 2017.

To calculate the sample size mean difference in $\mathrm{pH}$ was considered. ${ }^{18}$ Using the following formula ${ }^{19}$

$n=\left(\sigma \frac{Z_{1-\alpha / 2}+Z_{1-\beta}}{\mu \mathrm{A}-\mu \mathrm{B}}\right)$

Where:

$\mathrm{n}$ is the sample size

$\sigma$ is standard deviation $=0.75$

$\alpha$ is Type I error $=5 \%$

$\beta$ is Type II error, meaning $1-\beta$ is power $=20 \%$

$\mu$ is expected mean $(\mu \mathrm{A}=7.5$ and $\mu \mathrm{B}=7.2)$

The calculated sample size was 98 , rounded to 100 . Each group sample size consisted of 50 .

Collected data were entered in excel and analysed using $\mathrm{R}$ software version 3.2.2. Continuous variables were presented as mean and standard deviation and categorical variables were presented as count and percent. Two-way repeatedmeasures ANOVA was done to compare the means of two groups at various time points. Association between two categorical variables was tested using the chi-square test. $\mathrm{P}<$ 0.05 was considered as statistically significant

The patients satisfying the inclusion criteria were recruited during the study period.

\section{Inclusion Criteria}

1. Full-term singleton pregnant women undergoing elective caesarean section under the subarachnoid block (SAB).

2. The age group of $18-35$ years.

3. Patients who gave informed, written, valid consent.

\section{Exclusion Criteria}

1. Parturients having contraindications to regional anaesthesia.

2. Pregnancy induced hypertension (preeclampsia, eclampsia), antepartum haemorrhage, foetal malformations, placental abnormalities.

3. History of systemic disorders like cardiovascular disease, severe anaemia, cerebrovascular disease, autonomic dysfunction and neurological diseases.

4. Parturients on drugs that cause interactions with the study drugs like tricyclic antidepressants and MAO inhibitors, because phenylephrine is contraindicated in these cases.

The first 100 parturients who fulfilled the inclusion criteria were selected for the study and divided into two groups patients receiving phenylephrine (Group P) and 
patients receiving ephedrine (Group E). Parturients with odd numbers (e.g.; $1^{\text {st }}, 3^{\text {rd }}, 5^{\text {th }}$....and so on) were included in group $\mathrm{P}$, and those with even numbers (e.g.; $2^{\text {nd }}, 4^{\text {th }}, 6^{\text {th }} \ldots .$. and so on) were included in group E.

Group P: received phenylephrine 50 mcg IV bolus

Group E: received ephedrine $6 \mathrm{mg}$ IV bolus

- All patients who matched the inclusion criteria were assessed by a pre-anaesthetic examination.

- Patients were explained about the procedure and written informed consent was obtained.

- $\quad$ An IV line was established with 18G cannula and patients were preloaded with Ringer lactate $10 \mathrm{ml} / \mathrm{kg}$ body weight.

- Pre-medicated with Inj - ranitidine $50 \mathrm{mg}$ IV, Inj ondansetron $4 \mathrm{mg}$ IV 30 minutes before starting the procedure.

- The patient's basal parameters -Heart rate, oxygen saturation, blood pressure and ECG were recorded.

- Subarachnoid block was given by

- Midline approach

- $\quad$ Sitting / lateral position

- $\quad 25 \mathrm{G}-27 \mathrm{G}$ lumbar puncture needle

- $\quad$ L3 - L4 intervertebral space

- $2.2 \mathrm{ml}$ of $0.5 \%$ bupivacaine (heavy)

- Patients were turned supine and a wedge was placed below the right flank.

- Supplemental oxygen 5 lts / min was given through a face mask till the delivery of the baby.

- Heart rate and BP were monitored after every minute for the first 10 minutes and thereafter every 3 minutes.

- In patients who developed hypotension, defined as, fall in $\mathrm{BP} \geq 20 \%$ of the basal value / $\leq 90 \mathrm{mmHg}$ of systolic BP or presence of symptoms of hypotension like nausea, vomiting and dizziness, received either intravenous ephedrine $6 \mathrm{mg}$ or phenylephrine $50 \mathrm{mcg}$ based on the group allocation.

- If there was no increase in $\mathrm{BP}$, then a repeat dose of the same drug was given after 1 minute.

- If patients developed bradycardia, defined as HR $\leq 50$ bpm and symptomatic, then Inj. atropine $0.6 \mathrm{mg}$ IV was given.

- At delivery, $1 \mathrm{ml}$ of the cord blood was obtained and sent for blood gas analysis.

- $\quad$ Neonatal status was assessed by Apgar score following delivery.

\section{Parameters Observed}

- Baseline heart rate and BP.

- Time of intrathecal injection.

- Level of sensory block at $5 \mathrm{~min}$ assessed by pinprick method.

- $\quad$ BP and heart rate measured after SAB every min for 10 min, and every 3 min thereafter.

- Time after SAB at which hypotension developed.

- Incidence of bradycardia was noted.

- The number of bolus doses of study drug given.

- Apgar scores at $1 \mathrm{~min}$ and $5 \mathrm{~min}$ as assessed by the attending paediatrician.
- Immediately after delivery cord blood was obtained for acid-base status analysis.

\section{RESULTS}

In our study, there was no significant difference in age distribution between the two groups. In group $\mathrm{P}, 43$ patients out of 50 had no comorbidities, 3 patients had hypothyroidism, 2 had gestational diabetes, 1 had both hypothyroidism and gestational diabetes, and 1 patient was asthmatic. In group E, 34 patients out of 50 had no comorbidities, 12 patients had hypothyroidism, 3 had gestational diabetes, and 1 patient was asthmatic.

The mean $\mathrm{pH}$ in group $\mathrm{P}$ was $7.4+/-0.04$, while the mean $\mathrm{pH}$ in group $\mathrm{E}$ was $7.3+/-0.07$ and the difference in $\mathrm{pH}$ between the two groups was statistically significant with $\mathrm{P}$ value $<0.001$. The mean base excess in group $\mathrm{P}$ was $-1.9+$ $/-1.47$, and the mean base excess in group $\mathrm{E}$ was $-4.3+/-$ 2.56. The difference in base excess between the two groups was statistically significant with $P$ value $<0.001$ (Table 1 ).

\begin{tabular}{|c|c|c|c|c|c|c|c|c|c|}
\hline \multicolumn{7}{|c|}{ Group } & \multirow{3}{*}{$\mathbf{T}$} & \multirow{3}{*}{ Df } & \multirow{3}{*}{$\begin{array}{c}\mathbf{P} \\
\text { Value }\end{array}$} \\
\hline & \multirow[b]{2}{*}{$\mathbf{N}$} & \multicolumn{2}{|l|}{$\mathbf{P}$} & \multicolumn{3}{|c|}{$\mathbf{E}$} & & & \\
\hline & & Mean & SD & $\mathbf{N}$ & Mean & SD & & & \\
\hline $\mathrm{pH}$ & 50 & 7.4 & 0.04 & 50 & 7.3 & 0.07 & 3.98 & 98 & $<0.001$ \\
\hline Base excess & 50 & -1.9 & 1.47 & 50 & -4.3 & 2.56 & 5.81 & 98 & $<0.001$ \\
\hline & $T a$ & e 1. Th & Diffe & $n c$ & $n p H c$ & Bas & $\overline{\text { Exces }}$ & & \\
\hline
\end{tabular}

The mean Apgar score in group $\mathrm{P}$ at 1 minute after birth was $7.3+/-0.45$, and for group E was $7.3+/-0.50$. At 5 minutes after birth, the mean Apgar score in group $P$ was 9.0 $+/-0.40$, and for group E was $8.9+/-0.53$. The difference in Apgar scores between the two groups at 1 minute $(\mathrm{P}$ Value $=$ 0.999), and at 5 minutes ( $\mathrm{P}$ Value $=0.060$ ) was not statistically significant (Figure 1).

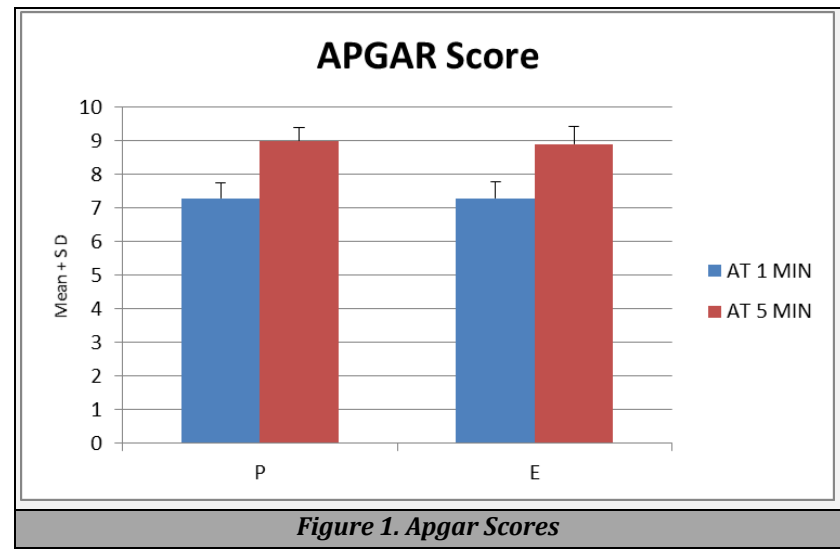

The difference between the baseline heart rates between the two groups was statistically insignificant. However, there was a statistically significant difference in heart rates between the two groups after receiving the subarachnoid block and vasopressor agent. Administration of ephedrine resulted in a higher heart rate response compared to the phenylephrine group (Figure 2). 


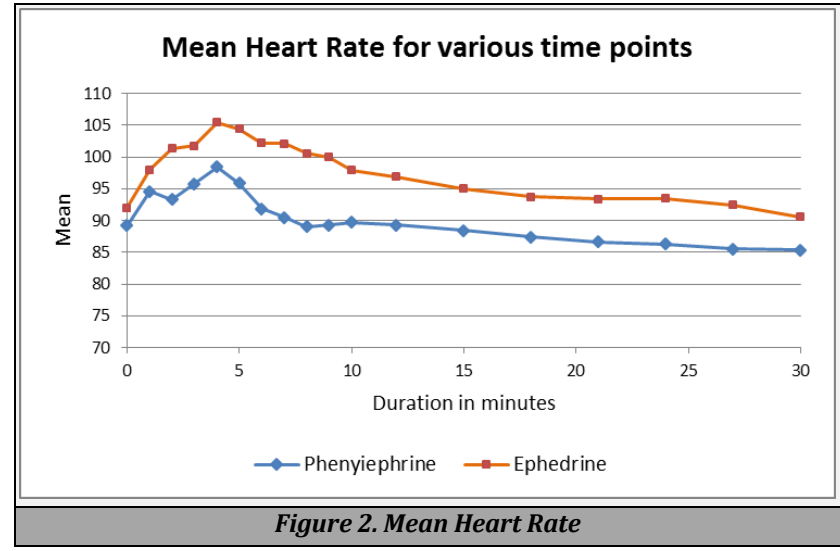

The two groups were compared in terms of systolic blood pressure and there was no statistically significant difference in systolic blood pressure between the two groups. The diastolic blood pressures in the two groups were comparable throughout the study period. There was no difference in terms of mean arterial pressure between the two groups during the study period, and at the time of delivery of the baby, the mean arterial pressure was within $10 \%$ from the baseline (Figure 3).

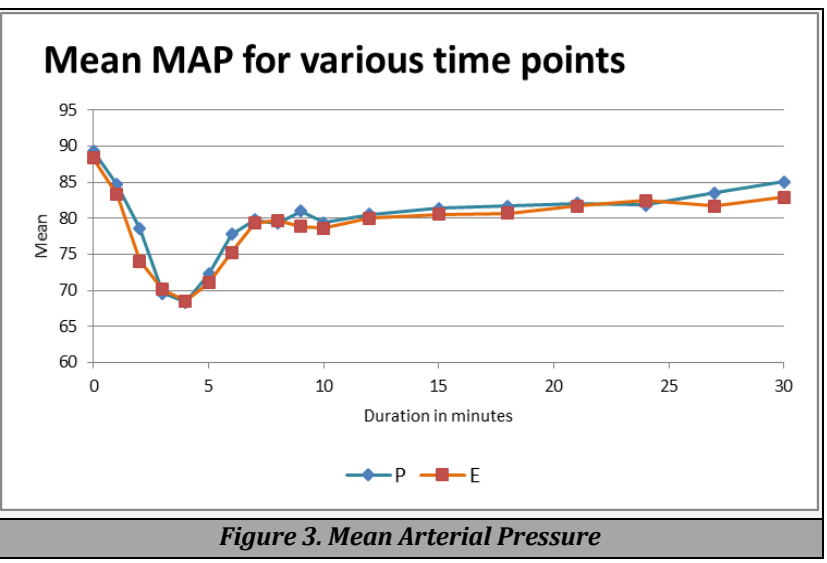

The number of drug doses administered in the two groups of patients to maintain blood pressure was similar. Around $52 \%$ of the patients in the phenylephrine group and $42 \%$ in the ephedrine group needed two rescue doses to maintain blood pressure. One patient in each group needed six doses to sustain normal blood pressure.

Only one patient in group P developed bradycardia (heart rate $52 \mathrm{bpm}$ ) with hypotension $67 / 32 \mathrm{mmHg}$, 3 minutes after subarachnoid block, and was given injection atropine $0.6 \mathrm{mg}$ intravenously which improved the heart rate, without causing any adverse consequences. The difference in the incidence of nausea and vomiting after subarachnoid block between the two groups was not statistically significant, p-value 0.674. In group E, 11 patients developed nausea, during the intraoperative period out of which 3 had vomiting, whereas, in group P, 8 patients developed nausea during the intraoperative period out of which 2 patients had vomiting (Figure 4).

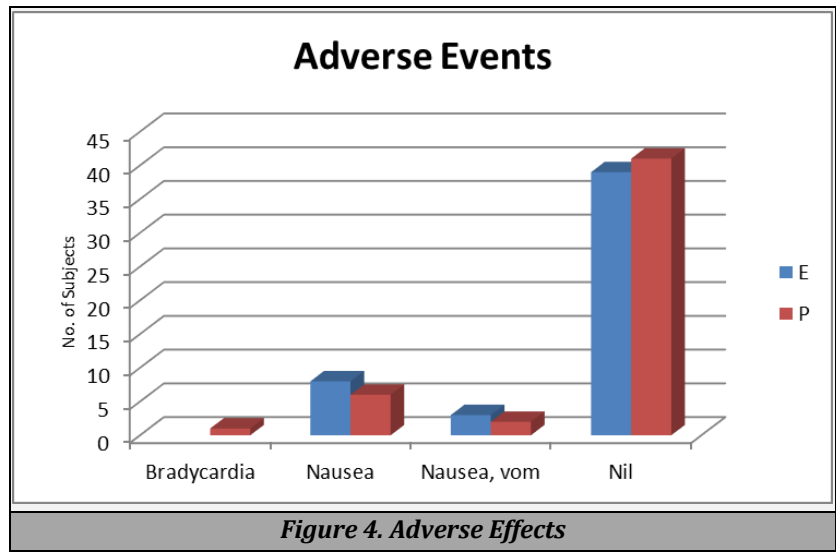

DISCUSSION

Spinal anaesthesia is the most preferred anaesthetic technique for caesarean sections. The common and troubling problem with spinal anaesthesia in gravid parturients is hypotension, and if persistent can endanger the life of both mother and child. Various studies and systematic reviews have compared phenylephrine and ephedrine for the management of post-spinal hypotension during caesarean sections. We evaluated the efficacy of these vasopressors and their effects on the new-born.

We observed that there was a significant difference in umbilical artery $\mathrm{pH}$ and base excess between the phenylephrine and ephedrine groups. Phenylephrine group showed higher $\mathrm{pH}$ values $7.40+/-0.04$ than ephedrine group $7.30+/-0.07(\mathrm{P}<0.001)$ and phenylephrine group showed lower base excess values $-1.9+/-1.47$ than ephedrine group $-4.3+/-2.56(\mathrm{P}<0.001)$. A similar observation was reported by Saravan et al. ${ }^{11}$ In their study, umbilical arterial blood gas analysis showed that $\mathrm{pH}$ was significantly higher for phenylephrine group 7.30+ / - 0.06 compared with ephedrine group $7.25+/-0.09(\mathrm{P}=0.01)$, and standard base excess was significantly lesser for phenylephrine group - $0.2+/-2.02$ than ephedrine group - 1.59+ / - $2.67(\mathrm{P}=0.03)$. Another study by Simin et al.20 also showed lower umbilical artery $\mathrm{pH}$ in the ephedrine group in comparison to the phenylephrine group, but the difference was not statistically significant $(\mathrm{P}=$ 0.12). Further, other umbilical artery parameters were also not different between the two groups. Prakash et al. ${ }^{4}$ also showed in their study that umbilical artery $\mathrm{pH}(\mathrm{P}=0.01)$ and base excess $(P<0.001)$ were significantly different in the ephedrine group than in the phenylephrine group. Our results are similar to these studies.

In our study, the neonatal outcome was shown to be similar between the two groups. Apgar scores at one minute $(\mathrm{P}=0.999)$ and five minutes $(\mathrm{P}=0.060)$ were comparable between the phenylephrine and ephedrine groups. Simin et al. ${ }^{20}$ in their study showed no difference in Apgar scores at one minute $(\mathrm{P}=0.22)$ and five minutes $(0.15)$, thus showing results similar to our study. Our results are in agreement with most of the studies. $4,21,22,18$

In a study, Thomas et al. ${ }^{7}$ also showed higher umbilical artery $\mathrm{pH}$ in the phenylephrine group than ephedrine group and on this basis supported the use of phenylephrine for maintenance of maternal arterial pressure during spinal anaesthesia for elective caesarean section. However, in our 
study, we have also observed neonatal Apgar scores at 1- and 5-minutes following delivery, which does not show a significant difference between the two groups. Hence, as per our study, both drugs are equally effective for the management of post-spinal hypotension in undergoing elective caesarean section.

Ephedrine is a mixed alpha and beta-agonist with predominant beta action and is thought to preserve uteroplacental blood flow. ${ }^{13}$ However, its use results in a lower umbilical artery $\mathrm{pH}$ than phenylephrine during caesarean section. ${ }^{23}$ It has been suggested that foetal betaadrenergic stimulation from ephedrine could be the cause of increased foetal acidosis. ${ }^{18}$ The stimulation of betaadrenergic receptors increases oxygen demand and anaerobic metabolism in the foetus. Ephedrine is more lipidsoluble than phenylephrine resulting in greater transplacental transfer. Moreover, the early metabolism and redistribution of ephedrine in the foetus occur to a lesser extent than that of phenylephrine. ${ }^{15}$ Consequently, despite increasing foetal oxygen supply, ephedrine results in increased foetal lactate concentration and decreased foetal pH. ${ }^{18}$ Although phenylephrine has been shown to result in better foetal acid-base status, there is no evidence of any difference in the overall clinical outcome of the neonate.

We also observed that phenylephrine is as effective as ephedrine when used in incremental bolus injections for maintenance of blood pressure following spinal anaesthesia in parturients undergoing caesarean section. Simin et al. ${ }^{20}$ in their study used phenylephrine and ephedrine in bolus doses of $100 \mathrm{mcg}$ and $5 \mathrm{mg}$ respectively and found no statistically significant difference in systolic blood pressure value at the same times between the two groups. In another study, Nazir et al. $^{22}$ used initial bolus doses of $100 \mathrm{mcg}$ of phenylephrine and $10 \mathrm{mg}$ of ephedrine at the time of subarachnoid block followed by rescue doses of $50 \mathrm{mcg}$ phenylephrine and $5 \mathrm{mg}$ ephedrine as required. They observed that the blood pressure response to either drug was equivocal between the two groups. The results of our study are consistent with these studies. Our results are also in accordance with the study by Adigun et al. ${ }^{24}$ who observed that both the vasopressors effectively restored both systolic and diastolic blood pressure. However, the results of a study by Magalhaes et al. ${ }^{14}$ are not in accordance with our results. In their study, the incidence of hypotension was $70 \%$ in the ephedrine group and $93 \%$ in the phenylephrine group, showing a statistically significant difference in the incidence of hypotension. Most other study results are in agreement with the results of our study.

Our study showed higher mean heart rates following ephedrine administration as compared with the phenylephrine group. One patient in the phenylephrine group developed bradycardia which responded to atropine without any adverse consequences. In a study by Mohta et al. ${ }^{18}$ the incidence of tachycardia following vasopressor administration was significantly higher in patients receiving ephedrine, whereas a greater incidence of bradycardia was seen in those receiving phenylephrine. A study by Gunda et al. ${ }^{25}$ also suggests that the incidence of tachycardia is higher in the ephedrine group compared to the phenylephrine group. The study conducted by Nazir et al. ${ }^{22}$ also found that maternal bradycardia occurred more frequently with phenylephrine than with ephedrine. This is explained by an increase in blood pressure that may lead to reactive bradycardia which is responsive to treatment with atropine. Our results are similar to the above studies. However, bradycardia was not clinically and statistically significant in our patients who received phenylephrine. However, in the study by Thomas et al. 71 out of 19 women required atropine for treatment of bradycardia in the phenylephrine group compared to 2 out of 19 women in the ephedrine group, thus showing a significant difference in the incidence of bradycardia.

Our study did not show a significant difference in the incidence of nausea and vomiting between ephedrine or phenylephrine for treating hypotension. These results are consistent with those of Mohta et al.18, Simin et al. ${ }^{20}$ and Prakash et al ${ }^{4}$.

\section{CONCLUSIONS}

We conclude from this study that in managing spinal induced hypotension for caesarean section, use of ephedrine showed a higher incidence of foetal acidosis in terms of lower mean umbilical artery $\mathrm{pH}$ and higher mean base excess values compared to that of phenylephrine. Both ephedrine and phenylephrine are equally effective in treating hypotension after spinal anaesthesia. Apgar score remained equally good in both the groups. Thus, either vasopressor can be used although phenylephrine can be a better choice in cases with foetal compromise or maternal tachycardia.

\section{Limitations of the Study}

In our study, only elective cases were taken and patients with pregnancy-induced hypertension were excluded from the study. There was an increased incidence of foetal distress and foetal acidosis in these patients and phenylephrine could be a better choice for controlling hypotension after subarachnoid block for which further studies need to be done.

Data sharing statement provided by the authors is available with the full text of this article at jemds.com.

Financial or other competing interests: None.

Disclosure forms provided by the authors are available with the full text of this article at jemds.com.

\section{REFERENCES}

[1] Sahu D, Kothari D, Mehrotra A. Comparison of bolus phenylephrine, ephedrine and mephentermine for maintenance of arterial pressure during spinal anaesthesia in caesarean section - a clinical study. Indian J Anaesth 2003;47(2):125-8.

[2] Chestnut DH. Chestnut's obstetric anesthesia principles and practice. $4^{\text {th }}$ edn. Philadelphia: Mosby 2009

[3] Cyna AM, Andrew M, Emmett RS, et al. Techniques for preventing hypotension during spinal anaesthesia for caesarean section. Cochrane Database Syst Rev 2006;4:CD002251.

[4] Prakash S, Pramanik V, Chellani H, et al. Maternal and neonatal effects of bolus administration of ephedrine and phenylephrine during spinal anaesthesia for 
caesarean delivery: a randomized study. Int J Obstet Anesth 2010;19(1):24-30.

[5] Lee A, Warwick D, Kee N, et al. A quantitative, systematic review of randomized controlled trails of ephedrine versus phenylephrine for the management of hypotension during spinal anaesthesia for caesarean section. Anesth Analg 2002;94(4):920-6.

[6] Balki M, Carvalho JCA. Intraoperative nausea and vomiting during cesarean section under regional anesthesia. Int J Obstet Anesth 2005;14(3):230-41.

[7] Thomas DG, Robson SC, Redfern N, et al. Randomised trial of bolus phenylephrine or ephedrine for maintenance of arterial pressure durine spinal anaesthesia for caesarean section. $\mathrm{Br} \mathrm{J}$ Anaesth 1996;76(1):61-5.

[8] Rout CC, Rocke DA. Prevention of hypotension following spinal anesthesia for cesarean section. Int Anesthesiol Clin 1994;32(2):117-35.

[9] Ayorinde BT, Buczkowski P, Brown J, et al. Evaluation of preemptive intramuscular phenylephrine and ephedrine for reduction of spinal induced hypotension during caesarean section. Br J Anaesth 2001;86(3):372-6.

[10] LaPorta RF, Arthur GR, Datta S. Phenylephrine in treating maternal hypotension due to spinal anaesthesia for caesarean delivery: effects on neonatal catecholamine concentrations, acid base status and Apgar scores. Acta Anaesthesiol Scand 1995;39(7):901-5.

[11] Saravanan S, Kocarev M, Wilson RC, et al. Equivalent dose of ephedrine and phenylephrine in the prevention of post-spinal hypotension in caesarean section. $\mathrm{Br} \mathrm{J}$ Anaesth 2006:96(1):95-9.

[12] James FM, Greiss FC, Kemp RA. An evaluation of vasopressor therapy for maternal hypotension during spinal anesthesia. Anesth Analg 1970;33:25-34.

[13] Ralston DH, Shnider SM, DeLorimier AA. Effects of equipotent ephedrine, metaraminol, mephentermine, and methoxamine on uterine blood flow in the pregnant eve. Anesthesiology 1974;40(4):354-70.

[14] Magalhaes E, Goveia CS, Ladeira LC, et al. Ephedrine versus phenylephrine: prevention of hypotension during spinal block for cesarean section and effects on the fetus. Rev Bras Anestesiol 2009;59(1):11-20.

[15] Kee WDN, Khaw KS, Tan PE, et al. Placental transfer and fetal metabolic effects of phenylephrine and ephedrine during spinal anesthesia for cesarean delivery. Anesthesiology 2009;111(3):506-12.

[16] Kee WDN, Khaw KS, Ng FF. Comparison of phenylephrine infusion regimens for maintaining maternal blood pressure during spinal anaesthesia for caesarean section. Br J Anaesth 2004;92(4):469-74.

[17] Moran DH, Perillo M, LaPorta RF, et al. Phenylephrine in the prevention of hypotension following spinal anesthesia for cesarean delivery. J Clin Anesth 1991;3(4):301-5.

[18] Mohta M, Aggarwal M, Sethi AK, et al. Randomized double-blind comparison of ephedrine and phenylephrine for management of post-spinal hypotension in potential fetal compromise. Int J Obstet Anesth 2016;27:32-40.

[19] Chow S, Shao J, Wang H, eds. Chapman \& Hall's CRC biostatistics series. Sample size calculations in clinical research. $2^{\text {nd }}$ edn. New York: Chapman and Hall/CRC 2008: p. 58.

[20] Simin A, Zahra F, Pouya HM, et al. Comparison of the effect of ephedrine and phenylephrine in treatment of hypotension after spinal anesthetic during cesarean section. Open J Obs Gyn 2012;2(3):192-6.

[21] Pinto V, Jaysundara NS, Abeysundara AB, et al. Use of phenylephrine as vasopressor of choice to prevent hypotension following spinal anaesthesia in LSCS. Srilankan J Anaesthesiol 2008;16(2):74-8.

[22] Nazir I, Bhat MA, Qazi S, et al. Comparison between phenylephrine and ephedrine in preventing hypotension during spinal anesthesia for cesarean section. J Obstet Anaesth Crit Care 2012;2(2):92-7.

[23] Habib AS. A review of the impact of phenylephrine administration on maternal hemodyanamics and maternal and neonatal outcomes in women undergoing cesarean delivery under spinal anesthesia. Anesth Analg 2012;114(2):377-90.

[24] Adigun TA, Amanor-Boadu SD, Soyannwo SD. Comparison of intravenous ephedrine with phenylephrine for the maintenance of arterial blood pressure during elective caesarean section under spinal anaesthesia. Afr J Med Sci 2010;39(1):13-20.

[25] Gunda CP, Malinowski J, Tegginmath A, et al. Vasopressor choice for hypotension in elective cesarean section: Ephedrine or phenylephrine. Arch Med Sci 2010;6(2):257-63. 